(c) American Dairy Science Association, 2003.

\title{
Use of Multi-Angle Laser Light Scattering and Size-Exclusion Chromatography to Characterize the Molecular Weight and Types of Aggregates Present in Commercial Whey Protein Products
}

\author{
T. Wang and J. A. Lucey \\ Department of Food Science, \\ University of Wisconsin-Madison, \\ 1605 Linden Drive, \\ Madison, WI 53706
}

\begin{abstract}
In this study, a range of commercial whey protein products were characterized by the use of size-exclusion chromatography coupled with a multi-angle laser light scattering (MALLS) detector. The MALLS system detected some very large-sized material that eluted close to void volume in all samples; this material was hardly detected by concentration detector. It was demonstrated by chitosan treatment that this peak was very small lipid globules or phospholipids, which gave the residual "cloudy" appearance in upper layers after ultracentrifugation of whey products. Composition, molecular weight, and the photo diode array (PDA) spectrum (200 to $400 \mathrm{~nm}$ ) of the major protein peaks, including: $\beta$-lactoglobulin (BLG), $\alpha$-lactalbumin (ALA), bovine serum albumin (BSA), immunoglobulin $\mathrm{G}$ ( $\mathrm{IgG}$ ) and some minor components were analyzed. The molecular weight of BLG, ALA, BSA, and IgG peaks in whey protein isolates (WPI) were 2.3 to $3.7 \times 10^{4}, 1.4$ to $1.6 \times$ $10^{4}, 4.8$ to $6.7 \times 10^{4}$, and 1.2 to $2.5 \times 10^{5} \mathrm{Da}$, respectively. Compared with WPI, WPC has similar major proteins, but more large-sized residual lipid material and different minor constituents such as lactose and nonprotein nitrogen, depending on various commercial samples and protein content. An improved TCA-precipitation method was applied to quantify glycomacropeptide (GMP) in whey proteins, which demonstrated that there was a very low concentration of GMP in WPI manufactured using an ion-exchange process. The molecular weight of GMP was found to be $\sim 8600 \mathrm{Da}$. Sizeexclusion chromatography MALLS was demonstrated to be a powerful technique for detailed analysis of the molecular weight of various proteins, aggregates and
\end{abstract}

Received March 12, 2002.

Accepted May 1, 2003.

Corresponding author: J. A. Lucey; e-mail: jalucey@facstaff. wisc.edu. minor components, such as GMP, in whey protein products.

(Key words: whey protein, size-exclusion chromatography, multi-angle laser light scattering, molar mass)

Abbreviation key: ALA $=\alpha$-lactalbumin, $\mathbf{B L G}=\beta$ lactoglobulin, DRI = differential refractive index, GMP = glycomacropeptide, $\mathbf{I E}=$ ion exchange, $\mathbf{L S}=$ light scattering, MALLS = multi-angle laser light scattering, $\mathbf{M F}=$ microfiltration, $\mathbf{M W}=$ molecular weight, $\mathbf{P D A}=$ photo diode array, SEC = size-exclusion chromatography, $\mathbf{U F}=$ ultrafiltration, $\mathbf{W P C}=$ whey protein concentrate, $\mathbf{W P I}=$ whey protein isolate.

\section{INTRODUCTION}

Whey protein products are widely used food ingredients because of their excellent functional (e.g., gelling) and nutritional properties. Whey proteins are valuable byproducts from the cheese-making industry. The manufacture, properties, and uses of whey proteins have been reviewed (Kinsella and Whitehead, 1989; Bottomley et al., 1990; Morr and Ha, 1993; de Wit, 1998). Manufacturing processes and conditions for whey proteins can vary from producer to producer. Nowadays, the manufacturing technology for whey proteins can be classified into two major categories: membrane technology, which includes cross-flow microfiltration (MF) and ultrafiltration (UF), and ion-exchange chromatography (IE). The major proteins present in whey include: $\beta$ lactoglobulin (BLG; $50 \%$, wt/wt), $\alpha$-lactalbumin (ALA; $\sim 20 \%$, wt/wt), immunoglobulins (e.g., IgG; $10 \%$ wt/wt), and BSA, ( 6\%, wt/wt) (Walstra and Jenness, 1984). Two of the most important whey protein products are whey protein concentrates (WPC; 34 to $80 \%$; wt/wt, protein) and whey protein isolates (WPI; $>90 \%$; wt/wt, protein). The typical production process for WPC includes UF-diafiltration, (optional step: evaporation) and spray drying. Microfiltration is also used to reduce the fat content for the higher protein WPC products. 
Two different approaches are used to produce WPI, 1) MF, UF-diafiltration, and spray drying and 2) IE coupled with concentration (evaporation or UF) and spray drying. Sweet whey, after separation from cheese curd, is often clarified to remove any remaining fines and pasteurized, and most of the residual fat is removed by centrifugal separation (as whey cream). In the MF/UF process used for WPI production, virtually all the fat remaining in the whey is removed during the MF step because it is effectively retained by this membrane. It should be noted that all the soluble whey proteins are concentrated in the MF/UF process, whereas in the IE process some proteins, e.g., glycomacropeptide (GMP), lactoferrin and small peptide fragments are not (usually) recovered (Deshler, 1999). Thus, there are nutritional and possibly functional differences between these two types of WPI.

Differences in chemical composition have been found between batches of whey proteins from the same and different manufacturers (Holt et al., 1999a, 1999b). The source of whey (acid or sweet) and fat content of the original cheese milk can influence composition and functional properties of WPC (Patel et al., 1990; de La Fuente et al., 2002). Because of its high content of disulfide and the free thiol group on BLG, whey proteins can be easily denatured and aggregate or gel upon changing temperature, $\mathrm{pH}$, or ionic strength (Shimada and Cheftel, 1989; de Wit, 1990; Schokker et al., 1999). Some differences have been reported in the size-exclusion chromatography (SEC) profiles obtained for different batches of WPC (Morr, 1985; Morr and Foegeding, 1990). Commercial WPC manufactured under similar conditions often have large variations in their physicochemical and functional properties (de Wit et al., 1988; Cayot and Lorient, 1997). Size-exclusion chromatography has been used extensively to study heat-induced aggregation of whey proteins (de Wit, 1990; Parris et al., 1993; Hollar et al., 1995). The functional properties of commercial whey protein products are influenced by processing conditions including heat treatment and mineral content (de Wit, 1990).

Size-exclusion chromatography is widely used to characterize the molecular weight of food materials. The approximate molecular weight of individual peaks can be determined using molecular weight standards. Light scattering (LS) has long been used as an absolute method to determine the molecular weight (MW), shape, and conformation of polymers (Wyatt, 1993). The use of multi-angle laser light scattering (MALLS) detector with a SEC system is a powerful new development in this field. In combination with concentration detectors such as UV and differential refractive index (DRI) this type of system can calculate the MW, zaverage root mean square radius $(R g)$, and concentra- tion of material eluting in small, individual slices of the entire SEC chromatogram. Size-exclusion chromatography MALLS has been used to characterize the MW and size distribution of protein particles in heated (pure) BLG solutions (Hoffman et al., 1997; Schokker et al., 2001) and in whey samples during the WPC manufacturing process (de La Fuente et al., 2002).

There do not appear to be any published articles on the weight-average molar mass and size distribution of molecules in whey protein products produced by different processes; this information could be useful in understanding the functional behavior of this important food ingredient. Holt et al. (1999a) used SEC-MALLS on whey products (one $76 \%$ protein WPC and two WPI samples produced using IE; however, no MW data were reported for the aggregates, only the composition of some of its major protein species. The aim of this study was to characterize the detailed MW and protein composition of a wide range of commercial whey protein products using SEC coupled with MALLS. With the growing interest in GMP and the differences that should occur in the GMP content in whey products produced by either IE or MF/UF techniques, we also wished to develop a rapid method to quantify GMP and its MW in various whey products.

\section{MATERIALS AND METHODS}

\section{Materials}

Seven commercial WPI samples and eight WPC samples were obtained from different dairy companies, which originated from United States, New Zealand, and Europe. An agglomerated or instantized WPI was also included in the study. Proximate analyses of these samples were supplied by the manufacturer and well as the principal technologies used in their manufacture (Table 1). IgG, BLG, ALA, BSA, GMP, orotic acid monohydrate, lactose standards, and high MW chitosan ( $90 \%$ deacetylation) were purchased from Sigma (Sigma Chemical Co., St. Louis, MO). The commercial GMP product (BioPURE-GMP) was obtained from Davisco (Davisco Foods International Inc., Le Sueur, MN). All chemicals used were of analytical grade obtained from Sigma. Filters were obtained from Millipore (Millipore Corp., Bedford, MA).

\section{Sample Preparation}

Whey protein solutions $(\sim 4.0 \%$, wt $/ \mathrm{wt}$, protein) were prepared in $20 \mathrm{~m} M$ imidazole, $50 \mathrm{~m} M \mathrm{NaCl}$, and $0.1 \%$ (wt/wt) $\mathrm{NaN}_{3}$ at $\mathrm{pH} 7.0$ that was prefiltered through a $0.025-\mu \mathrm{m}$ filter. Samples were dissolved for $\sim 4 \mathrm{~h}$ at room temperature $\left(\sim 22^{\circ} \mathrm{C}\right)$. Whey protein solutions $(\sim 12 \mathrm{~g})$ were ultracentrifuged at $100,000 \times g$ for $90 \mathrm{~min}$ at $20^{\circ} \mathrm{C}$ 
Table 1. Proximate chemical composition and processing technology used for the commercial samples of whey protein isolate (WPI) and whey protein concentrate (WPC) (as reported by manufacturers).

\begin{tabular}{lllllll}
\hline & \multicolumn{5}{c}{ Chemical composition \% (wt/wt) } & \\
\cline { 2 - 5 } Samples & Protein & Fat & Lactose & Ash & Moisture & Comments \\
\hline WPI & & & & & & \\
A & 92.0 & 1.0 & 1.0 & 3.0 & 4.0 & MF/UF \\
B & 90.5 & 0.4 & 0.8 & 3.1 & 4.4 & MF/UF \\
C & 97.4 & 0.4 & 0.6 & 1.6 & 4.0 & IEA/UF \\
D & 97.7 & 0.3 & 0.5 & 2.0 & 4.9 & IEA/UF \\
E & 94.0 & 1.0 & 1.0 & 3.0 & 5.0 & MF/UF \\
F & 92.0 & 0.4 & 1.6 & 2.7 & 4.5 & MF/UF \\
G & 91.0 & 1.0 & 1.0 & 3.0 & 4.0 & MF/UF (instantized) \\
WPC & & & & & & \\
H & 73.2 & 9.5 & 6.0 & 4.0 & 4.0 & UF \\
I & 34.0 & 4.5 & 48.5 & 8.0 & 5.0 & UF \\
J & 35.7 & 3.2 & 51.1 & 6.0 & 4.0 & UF \\
K & 36.4 & 3.4 & 56.0 & 1.0 & 2.6 & UF \\
L & 34.5 & 3.5 & 52.5 & 7.0 & 2.5 & UF \\
M & 80.0 & 7.0 & 5.5 & 3.0 & 4.5 & UF \\
N & 33.8 & 4.0 & 51.2 & 7.0 & 4.0 & UF \\
O & 80.5 & 7.0 & 4.5 & 3.0 & 5.0 & \\
\hline
\end{tabular}

in a temperature-controlled centrifuge (L7 ultracentrifuge, Beckman, Fullerton, CA), and about 2 to $3 \mathrm{ml}$ of the subnatant was collected carefully using a $10-\mathrm{ml}$ syringe by puncturing through the wall of centrifuge tube. The subnatant was then filtered through $0.22-\mu \mathrm{m}$ filter for WPI or $0.1-\mu \mathrm{m}$ filter for WPC samples prior to injection into the SEC columns. Ultracentrifugation could be omitted, but the intensity of light scattering signal from the first peak that eluted close to the void volume required the use of a very dilute solution (i.e., $<1 \%$, wt/wt, protein).

\section{Chitosan Clarification}

Chitosan was used to remove residual lipids in whey (Hwang and Damodaran, 1995). One percent chitosan solution (in 10\%, vol/vol, acetic acid) was added to whey protein solution to a final concentration of $0.01 \%$ (vol/ vol). The $\mathrm{pH}$ of this solution was adjusted to 4.5 by the addition of $1 \mathrm{M} \mathrm{HCl}$. The mixture was incubated for 30 min at room temperature $\left(\sim 22^{\circ} \mathrm{C}\right)$ and centrifuged at $1200 \times g$ for 5 min (CR3i, Jouan Inc., Winchester, VA) at $22^{\circ} \mathrm{C}$. The supernatant was collected, and the $\mathrm{pH}$ of solution was readjusted to 7.0 by the addition of $1 \mathrm{M}$ $\mathrm{NaOH}$. The whey solution was then ultracentrifuged and collected as described previously.

\section{Size-Exclusion Chromatography with Multi-Angle Laser Light Scattering}

Separation of whey protein subnatant solution was carried out by SEC using Superose 6HR 10/30 and Superose 12HR 10/30 columns (Amersham Pharmacia Biotech $\mathrm{AB}$, Uppsala, Sweden) connected in series and attached to a Waters HPLC system (Waters Corp., Milford, MA) operating at room temperature $\left(\sim 22^{\circ} \mathrm{C}\right)$. A solution containing $20 \mathrm{~m} M$ imidazole, $50 \mathrm{mM} \mathrm{NaCl}$ and $0.1 \%$ (wt/wt) $\mathrm{NaN}_{3}$ at $\mathrm{pH} 7.0$ (filtered through 0.025 $\mu \mathrm{m}$ ) was used as an eluent buffer. All samples were filtered before injection. Sample injection volume was $50 \mu \mathrm{l}$, nominal flow rate was $0.4 \mathrm{ml} / \mathrm{min}$ and separation was performed at room temperature $\left(\sim 22^{\circ} \mathrm{C}\right)$. Spectrum analysis was conducted by a photo diode array (PDA) detector (Waters Corp., Milford, MA, model 996) operating over the range 200 to $400 \mathrm{~nm}$, with a scanning rate of $1.0 / \mathrm{s}$ and a resolution of $1.2 \mathrm{~nm}$. A DAWN-EOS MALLS photometer (Wyatt Technology, Santa Barbara, CA) fitted with a helium-neon laser $(\lambda=690 \mathrm{~nm})$ and a K5-flow cell, combined with a differential refractive index (DRI) detector (Waters Corp; model 2410) was used for calculation of MW of different whey proteins. Light scattering data from MALLS were processed with ASTRA (version 4.73 04) and HPLC data including RI, UV (280 nm), and PDA spectrum were processed by Waters Millennium version 3.20.

\section{Determination of the Amount of GMP in WPI}

Three milliliters of each WPI sample (10\%, wt/vol) were prepared in 15-ml centrifuge tubes and vortexed at full speed for $20 \mathrm{~s}$ and allowed to stand for $30 \mathrm{~min}$ before vortexing again for another $20 \mathrm{~s}$. An equal volume of $14 \%$ (wt/wt, $14 \mathrm{~g}$ of TCA $+86 \mathrm{~g}$ of water) TCA solution was added to the protein solution and the mixture was vortexed for another $10 \mathrm{~s}$ at full speed. The TCA-protein mixture was allowed to stand overnight $(\sim 14 \mathrm{~h})$ at room temperature $\left(\sim 22^{\circ} \mathrm{C}\right)$ before centrifugation at $3000 \times g$ at $6^{\circ} \mathrm{C}$ (CR3i, Jouan Inc., Winchester, 
VA). The supernatant was collected and filtered through $0.2 \mu \mathrm{m}$ before injection into the SEC-MALLS system. A phosphate buffer ( $\mathrm{pH}$ 5.6) was prepared according to Lieske and Konrad (1996), filtered through $0.025 \mu \mathrm{m}$ and was used as eluent for SEC-MALLS.

A standard curve of GMP was made by injecting a series of GMP (obtained from Sigma Chemical Co.) solutions of known concentrations. The DRI detector was used as concentration detector since the MW of GMP could be calculated simultaneously as this peak eluted from the SEC columns.

Recovery rate of GMP by this TCA procedure was estimated by precipitating relatively pure GMP (BioPURE-GMP) prepared with a similar concentration as the GMP concentration present in WPI samples. The purity of BioPURE-GMP was first estimated by injecting unprecipitated GMP (dissolved in water) into the SEC-MALLS system and the purity of the mass injected was obtained from the standard curve. Then, BioPURE-GMP was precipitated by the same TCA procedure described previously. Finally, the recovery rate of GMP was calculated by determining the concentration of GMP in the TCA-treated sample. A typical specific refractive index increment $(d n / d c)$ value of protein $(\sim 0.185 \mathrm{ml} / \mathrm{g})$ was used to estimate the MW of GMP.

\section{Data Treatment}

The DAWN-EOS MALLS detector simultaneously provides up to $16 \mathrm{LS}$ chromatograms, each at a different scattering angle, for a polymer solute as it emerges from the SEC column (Wyatt, 1993). Additional chromatographs from a concentration detector have to be used for the determination of MW. By dividing the LS signals with the concentration signals obtained from either the DRI or UV detectors, which used a $d n / d c$ value or extinction coefficient $(\varepsilon)$, respectively, and assuming a second virial coefficient $\left(\mathrm{A}_{2}\right)$ of zero (Wen et al., 1996), the MW and $R_{g}$ of polymer solute eluting in each angle were calculated with a first-order Debye fit (higher order polynomials were also tried but gave a poorer fit to the data). Extrapolating this fitted curve to Y-intercept provides MW and the slope of this curve at low angles gives $R_{g}$. With the ASTRA software it was also possible to realign (overlay) the SEC profiles from the different detectors caused by volume delays between units such as the UV and DRI detectors. The coefficient of variation between replicate MW measurements was typically $<3 \%$; within a single run the ASTRA software calculated averages and standard deviations of the MW and $R_{g}$ for each peak.

The calibration of LS detectors was performed by measuring the light scattering intensity of filtered HPLC quality toluene, which has a known Rayleigh

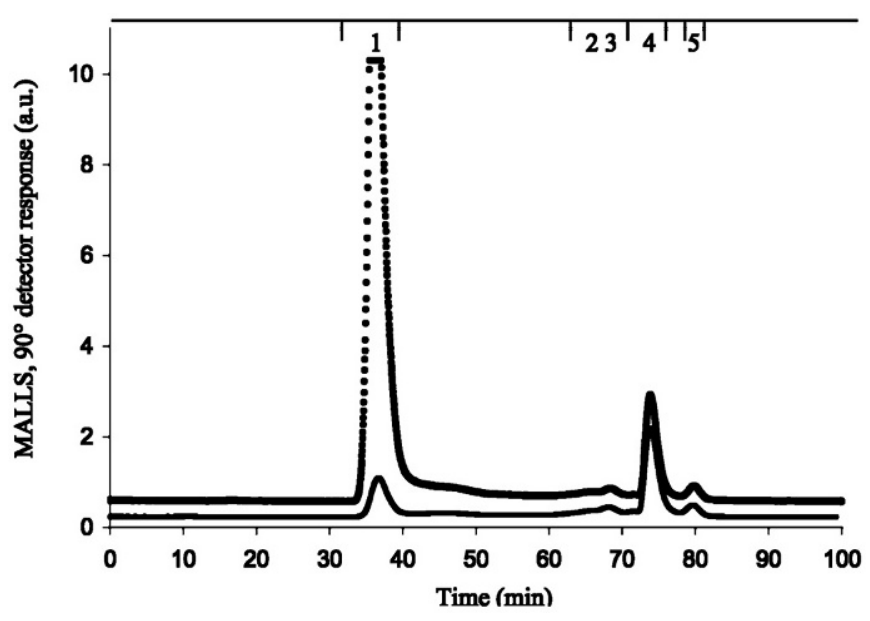

Figure 1. Multi-angle laser light scattering (MALLS) $90^{\circ}$ detector responses during size-exclusion chromotography (SEC) of a $4 \%$ commercial whey protein isolates sample $\mathrm{A}(\bullet \bullet)$ and its subnatant after ultracentrifugation (-). Numbers indicate peaks.

ratio at $90^{\circ}$ angle. The responses of LS intensity of the photodiodes arrayed around the scattering cell were normalized to the diode at $90^{\circ}$ with an isotropic BSA sample (monomeric BSA with a nominal molecular weight of $66 \mathrm{kDa}$ ). The $d n / d c$ value is a constant for whey proteins, which is $\sim 0.185 \mathrm{ml} / \mathrm{g}$ (Huglin, 1972) and $\varepsilon$ values are 661,960 , and $2030 \mathrm{~cm}^{2} / \mathrm{g}$ for BSA, BLG and ALA, respectively (Pace et al., 1995).

\section{Statistical Analysis}

Calculated MW data from SEC-MALLS were analyzed using the general linear models (GLM) of SAS program, and least significant differences $(P<0.05)$ between samples were determined using Scheffe test (SAS, 1999). Each sample was analyzed at least three times.

\section{RESULTS AND DISCUSSION}

Typical SEC-MALLS (responses from the $90^{\circ} \mathrm{LS}$ detector) profiles for a $4 \%$ (wt/wt) WPI and WPC solution are shown in Figures 1 and 2, respectively. During SEC the MALLS system clearly detected large aggregated material that eluted close to the void volume (36 to 38 min, peak 1) in both WPI (Figure 1) and WPC (Figure 2) samples. The size of this peak varied with different samples, but it was much larger in WPC samples (probably due to their higher fat content). A similar peak was observed by Lucey et al. (2000) and de La Fuente et al. (2002) in sodium caseinate and whey samples, respectively. In ultracentrifuged samples, the size of peak 1 , which is probably due to some residual lipid 


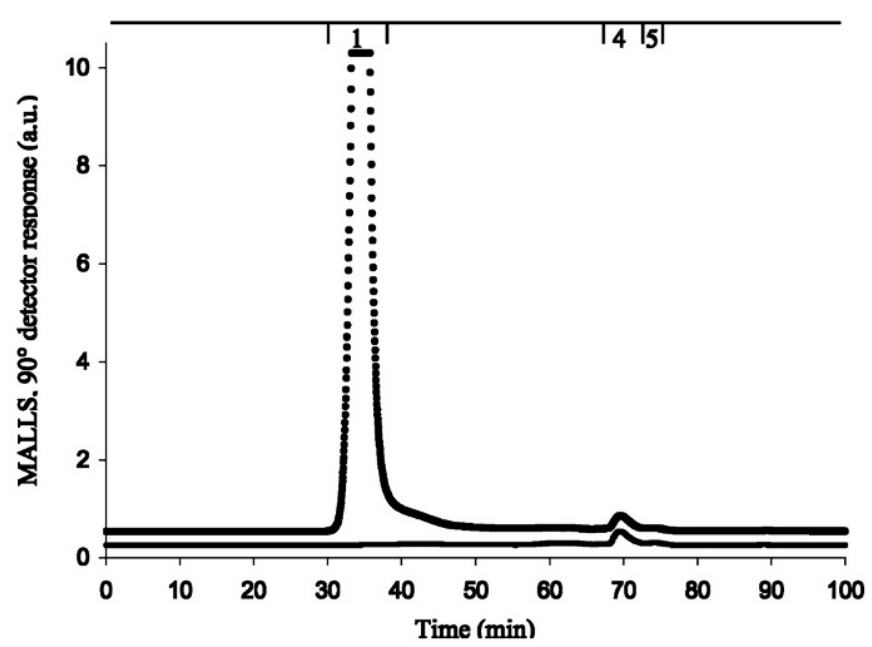

Figure 2. Multi-angle laser light scattering (MALLS) $90^{\circ}$ detector responses during size-exclusion chromotography (SEC) of a $4 \%$ commercial whey protein concentrate (WPC) sample I subnatant after

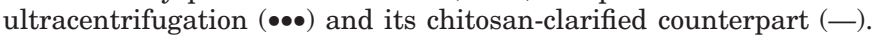
WPC samples prior to MALLS-SEC without ultracentrifugation were not tested (due to their high residual lipids content). Numbers indicate peaks.

material, was greatly reduced. All subsequent SECMALLS experiments therefore were performed on ultracentrifuged samples. Since residual lipids decrease the foaming properties of whey proteins (Morr and Ha, 1993), methods such as precipitation using chitosan have been developed for the selective removal of these lipids (Hwang and Damodaran, 1995), which we also performed here and the results are shown in Figure 2. Peak 1 nearly disappeared completely after chitosan treatment, which indicates that materials in this peak were residual lipids that were mainly negatively charged, e.g., phospholipids. These lipids formed a complex with chitosan at $\mathrm{pH} 4.5$, where the lipids were negatively charged and chitosan was positively charged.

The SEC-MALLS profiles for all the WPI samples are shown in Figure 3. The size of the first peak varied in the WPI samples, presumably reflecting differences in how efficiently residual lipids were removed during commercial processing (e.g., clarification, MF). The SEC-UV-DRI profiles for $4 \%$ (wt/wt) WPI solutions are shown in Figure 4. There did not appear to be any very large whey protein aggregates in any of the WPI samples, which suggests that relatively mild processing conditions (e.g., heat treatment) and extra purifications were used in their manufacture (or that any large aggregates were removed by the ultracentrafugation/filtration steps). Immunoglobulin G, BSA, BLG, and ALA were identified using their HPLC standards as peaks $2,3,4$, and 5 , respectively. Because all whey protein

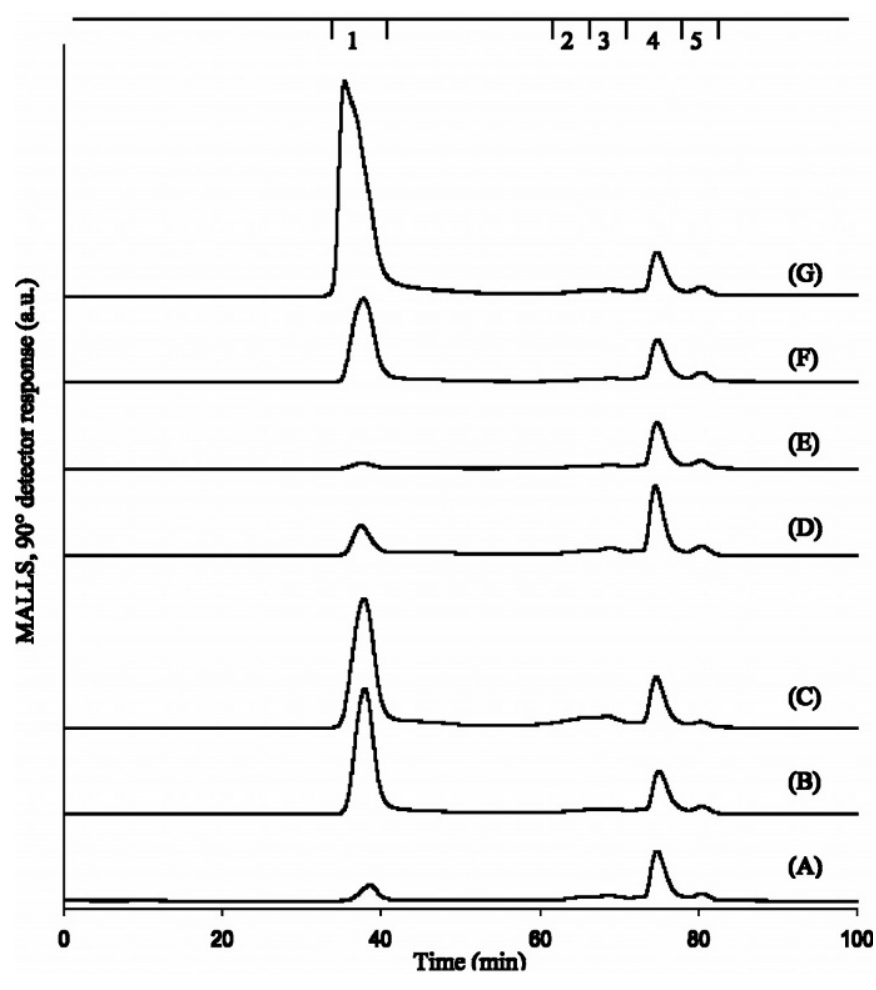

Figure 3. Size-exclusion chromatography, multi-angle laser light scattering (SEC-MALLS) elution profiles for different $4 \%$ commercial whey protein isolates samples (A to G) for the LS response at $90^{\circ}$. All samples were ultracentrifuged. Numbers indicate peaks.

solutions were prepared based on same total mass concentration, the height of major protein peaks: BLG (peak 4) or ALA (peak 5) either from UV or DRI, represents sample concentration. The peak heights of BLG in WPI ( $>90 \%, w t / w t$, protein) and high protein $(\sim 80 \%$, $\mathrm{wt} / \mathrm{wt}$, protein) WPC were between three to two times as high as those in low protein $(\sim 34 \%$, wt/wt, protein) WPC, respectively. These results agree with their corresponding protein content reported by the manufacturers. The peak (from DRI detector) height ratio of BLG to ALA, which indicates the concentration distribution of BLG and ALA, was in the range of 2.21 to 2.97. The average concentration ratio of BLG to ALA was 2.61, which is similar to the ratio of BLG to ALA in milk (Walstra and Jenness, 1984). The BLG and ALA contents of WPI samples ranged from 48 to $73 \%$ and 15 to $21 \%$ (of total area in DRI chromatographs), respectively. These results are similar to those previously reported by Morr and Foegeding (1990). Higher BLG and ALA contents were found in WPI samples produced using IE due to the very low GMP content.

Because it is possible that there was some adsorption of whey protein by the SEC columns (Holt et al., 1999a; 1999b), IgG, BSA, BLG, and ALA standards were not 

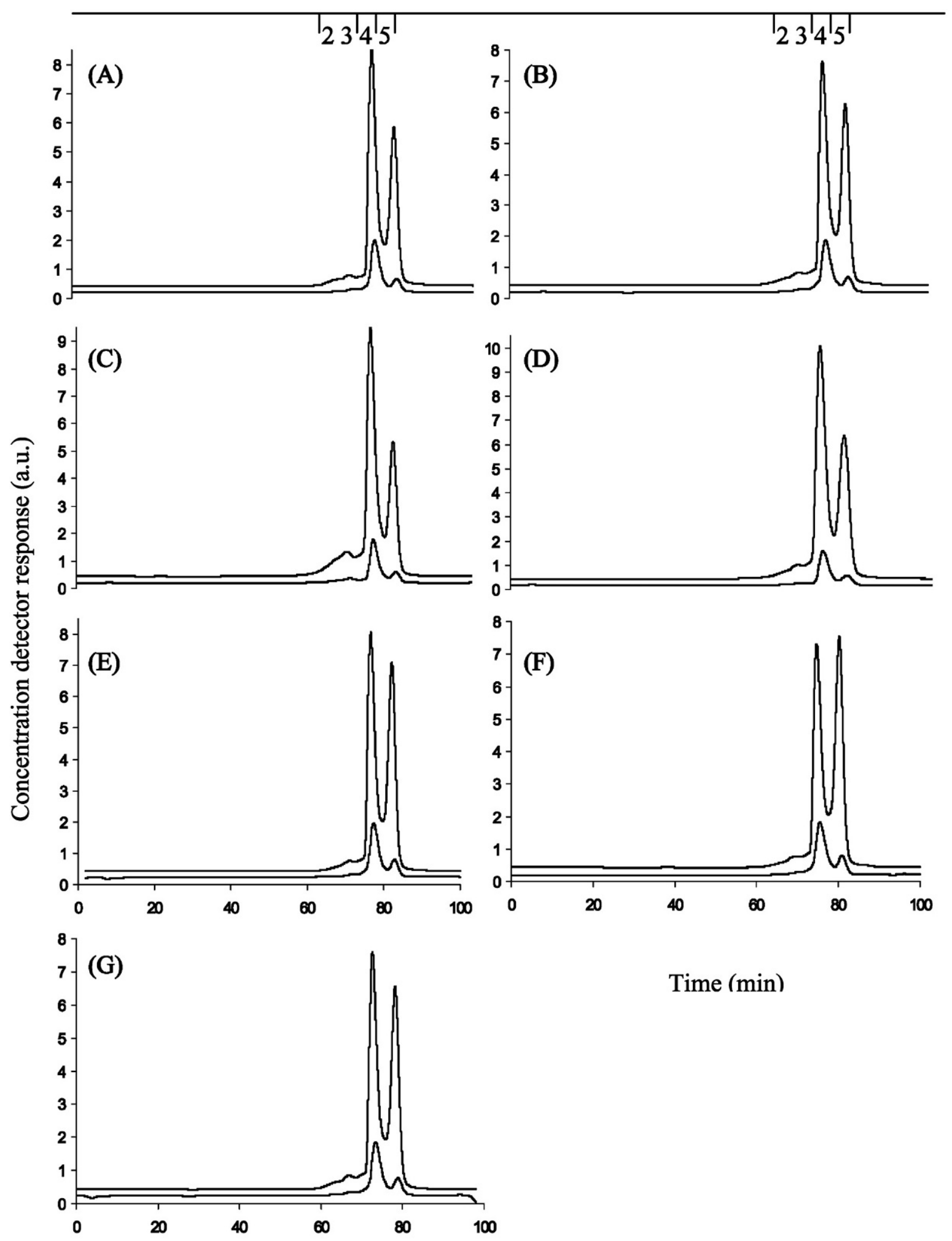

Time (min)

Time (min)

Figure 4. Concentration detectors, refractive index and UV responses for the different whey protein isolate (4\%, wt/wt) subnatants (samples A to G) after ultracentrifugation. The UV $(280 \mathrm{~nm})$ response is the upper curve in each graph. Numbers indicate peaks. 
used for quantification of the absolute concentration of these proteins in our samples. Instead, the relative content of the individual whey proteins in the WPI samples was estimated from the area under the SECDRI profile (Table 2). Due to the poor separation between IgG, lactoferrin, and BSA, their contents were calculated together.

The SEC-UV-DRI profiles for 4\% (wt/wt) WPC solutions are shown in Figure 5. In all WPC samples peak 1 (detected by UV at $280 \mathrm{~nm}$ ), i.e., mostly residual lipid fraction (e.g., phospholipids), was largely due to the higher fat content in WPC compared to WPI. Besides the major proteins in the whey: IgG (peak 2), BSA (peak 3), BLG (peak 4), and ALA (peak 5), a number of minor components, unknown (peak 6), lactose (peak 7), orotic acid (peak 8), and unknown (peak 9) were present in the low protein content WPC ( $\sim 34 \%$, wt/wt, protein). Similar results were reported for fresh Cheddar cheese whey (Law et al., 1993). These minor components were either absent or only present at very low concentrations in the high protein content WPC $(\sim 80 \%$, wt/wt, protein $)$ and WPI (>90\%, wt/wt, protein). Presumably, they were removed due to the extra purification procedures involved in the manufacturing of higher protein content WPC or WPI. The peak (from DRI detector) height ratio of BLG to ALA was in the range of 1.71 to 2.84. The average concentration ratio of BLG to ALA was 2.16. A relatively high ALA content was observed in sample H. No large MW aggregates were found; similar trends were reported for whey samples taken during the WPC manufacturing process (de La Fuente et al., 2002).

The PDA spectrum analysis of $\sim 34 \%$ (wt/wt) protein WPC components in peaks $1,2,3,4,5,6,8$, and 9 are shown in Figure 6 . The spectrum analysis of peak 1 clearly indicates that it had a unique profile compared to the other peaks with one maximum absorbance at $237 \mathrm{~nm}$, which is similar to the smaller maximum peak observed in the usual whey protein spectrum. The typical whey proteins, such as IgG (peak 2), BSA (peak 3), BLG (peak 4), ALA (peak 5), and unknown (peak 6), NPN: orotic acid (peak 8), have two maxima at 234 to $237 \mathrm{~nm}$ and 278 to $281 \mathrm{~nm}$. Their overall spectra were also very similar. Unknown peak 9 has $\mathrm{MW}<174$ (larger retention time than orotic acid, MW $=174 \mathrm{Da}$ ), one maximum at $291 \mathrm{~nm}$ and different spectrum profile from other proteins, which may suggest that it was another NPN. Glycomacropeptide had the same retention time as BLG, but totally different spectrum profile in $\mathrm{pH} 7.0$ buffer (results not shown).

The chromatographic profiles from the DRI detector overlaid with the calculated MW of WPI and WPC samples are shown in Figure 7. The peaks were identified according to elution time of their corresponding standards. The summary of calculated MW from different

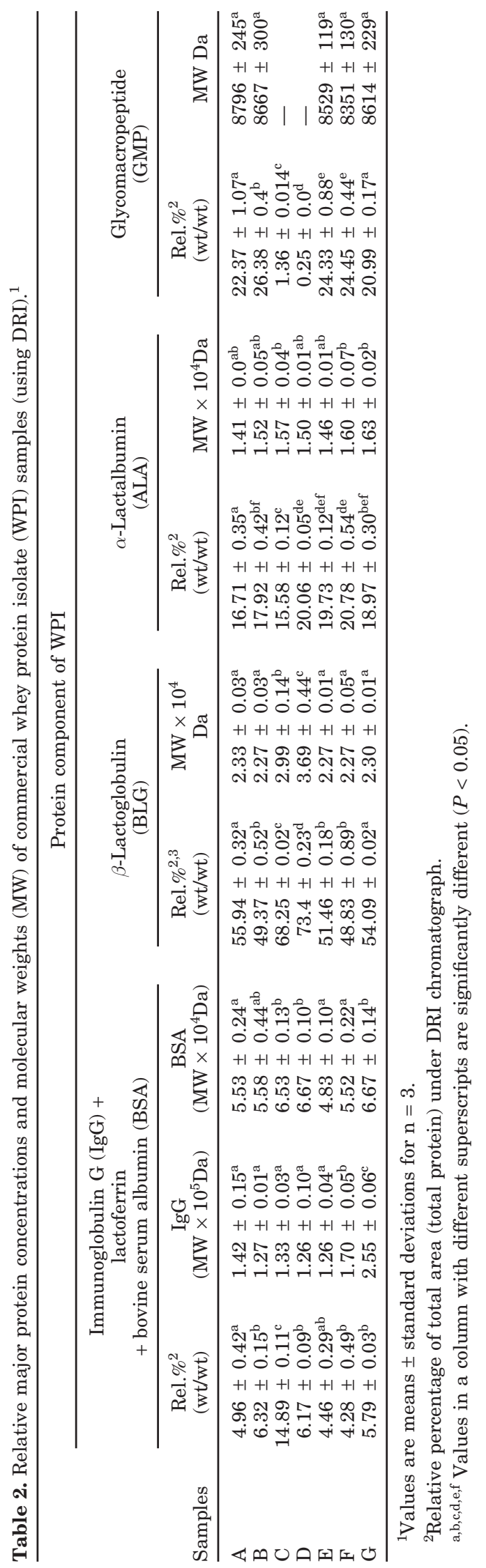




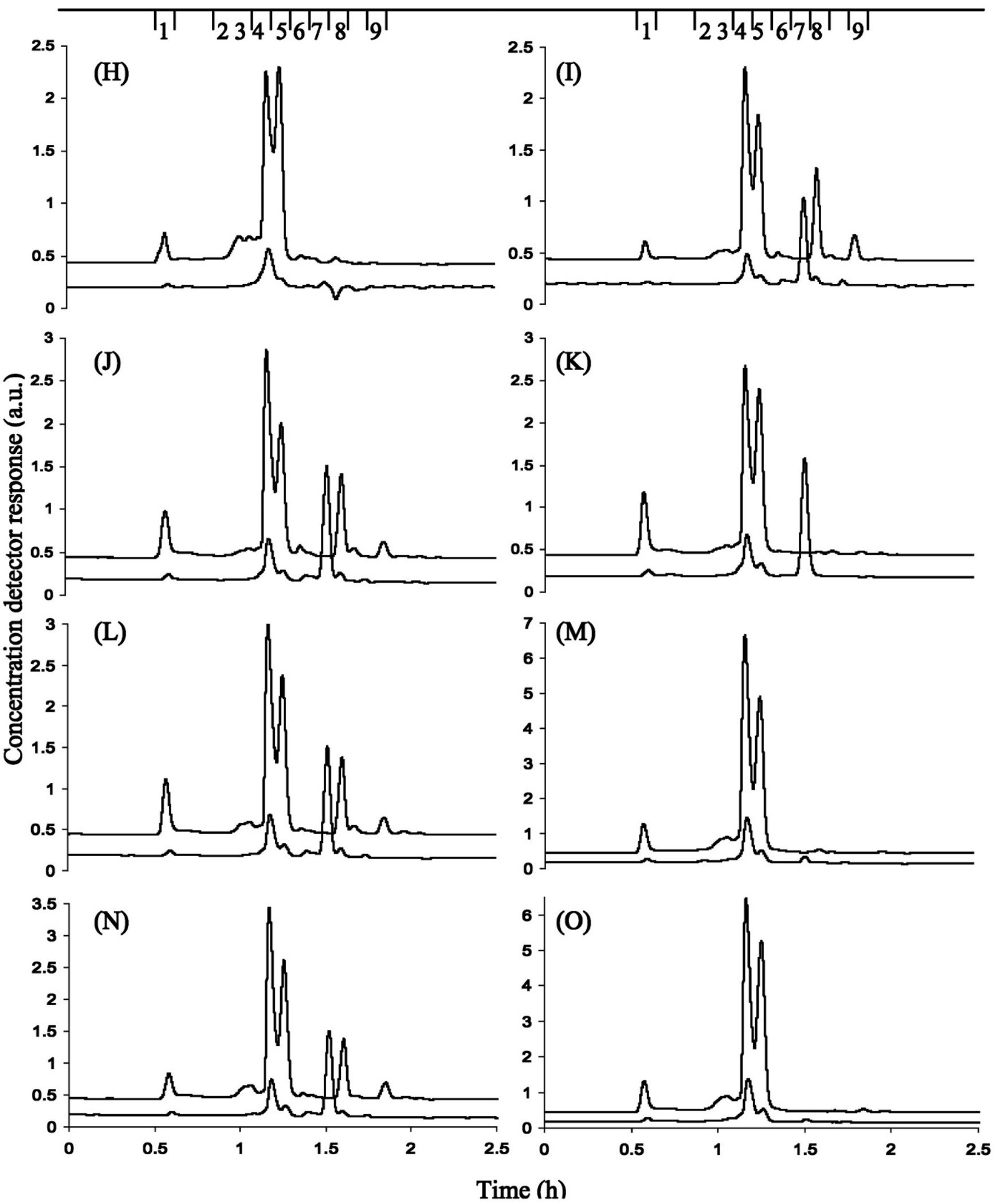

Figure 5. Concentration detectors, refractive index, and UV responses for the different whey protein concentrate (4\% wt/wt) subnatants (samples $\mathrm{H}$ to $\mathrm{O}$ ) after ultracentrifugation. The UV $(280 \mathrm{~nm})$ response is the upper curve in each graph. Numbers indicate peaks. 


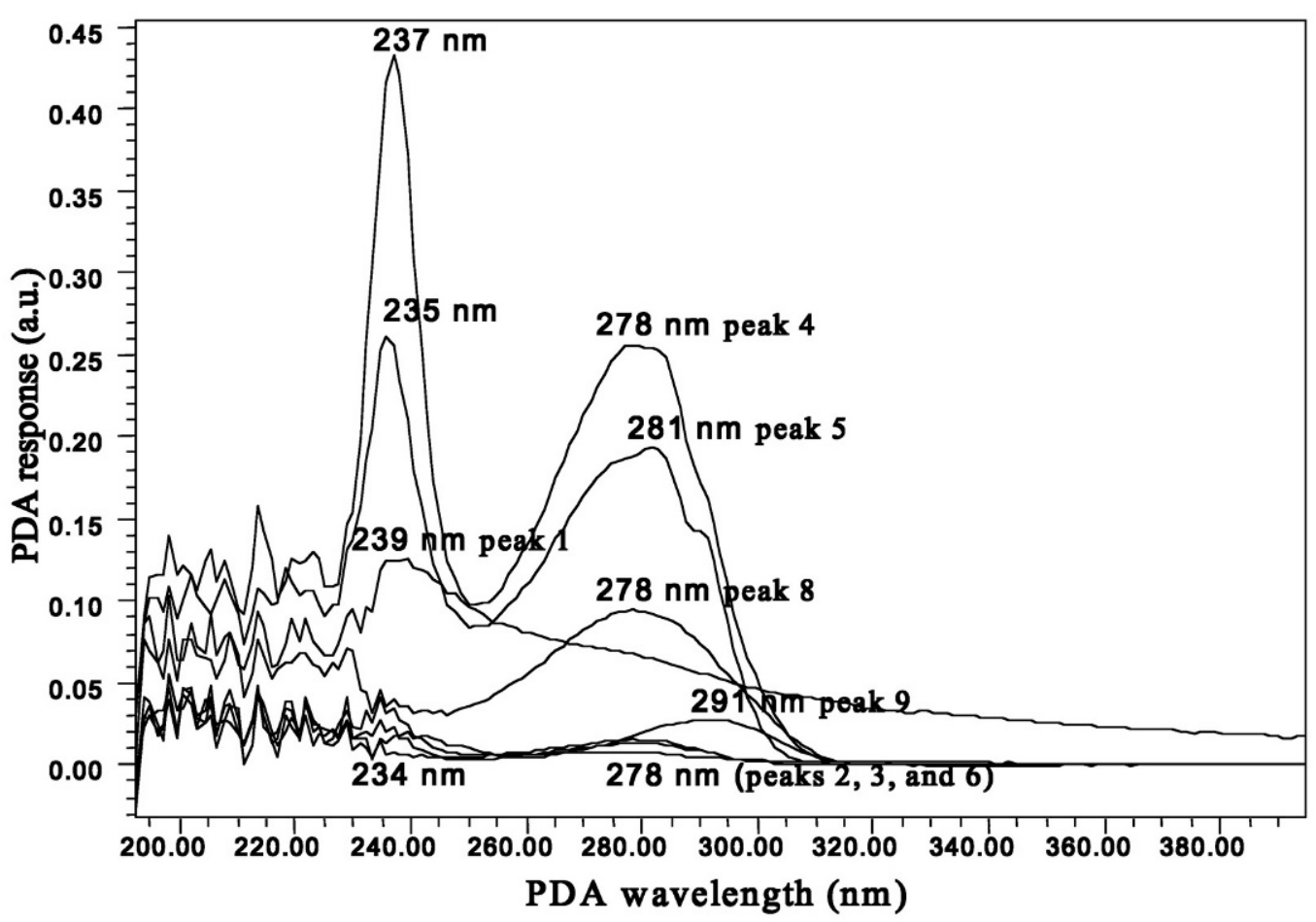

Figure 6. Photo diode array spectrum $(200-400 \mathrm{~nm})$ profiles of the main peaks obtained for a typical whey protein concentrate sample (34\% protein, sample I) subnatant after ultracentrifugation and separated by size-exclusion chromatography (SEC). The number (e.g., 237 $\mathrm{nm}$ ) for each peak represents the wavelength for maximum absorbance detected for an individual peak after SEC.

WPI samples is listed in Table 2. Statistical analysis of the relative peak area and MW of proteins indicate some significant differences among these WPI samples $(P<0.05)$. There were some problems in the estimation of the MW of IgG, which had the closest elution time to peak 1 . The higher the concentration of lipid residual, the higher the LS signal peak carryover effect was, which resulted in a larger estimated MW for IgG. The MW of IgG was 126 to $171 \mathrm{kDa}$, and it varied compared to the commercial SEC standard IgG of $158 \mathrm{kDa}$ (Law et al., 1993). One apparently large MW of IgG (255 kDa) from sample G (instantized WPI) may have been caused by the very large carryover from additional lipid or lecithin of the LS signal from peak 1.

No obvious very high molecular protein aggregates were observed, which is similar to results reported previously (Holt et al., 1999a, 1999b). The calculated MW of BSA (48 to $66 \mathrm{kDa}$ ) was slightly smaller than the standard monomer BSA (66 kDa). The MW of BLG in different WPI samples ranged from 22 to $37 \mathrm{kDa}$, which was between the MW of its monomer $(18 \mathrm{kDa})$ and dimer $(36 \mathrm{kDa})$. This may suggest that there is an equilibrium between BLG dimer and its monomer at $\mathrm{pH} 7$ (Schokker et al., 1999). The calculated MW of ALA ranged from 14 to $16 \mathrm{kDa}$, which was slightly higher than its standard $(14 \mathrm{kDa})$.
A comparison of MW of major proteins from WPI samples calculated using DRI or UV is given in Table 3 . Because of the higher sensitivity of UV detector $(\sim 100$ times higher) than DRI, the MW calculated by UV tended to be more consistent and accurate. The overall MW of BLG and ALA calculated from WPC samples was 28 to $37 \mathrm{kDa}$ and 25 to $29 \mathrm{kDa}$, respectively, which are not listed here because the relative large carry over of LS signal from lipid residuals (peak 1), which significantly affected the estimation of their MW.

Standard curve of GMP shows a good linear relationship between the peak area and the amount of GMP injected. The result is also reflected by the following equation:

$$
D R I(\text { area })=1.622 \times 10^{7} x(m g) \quad r^{2}=0.9999
$$

where, $D R I$ (area) is the DRI detector response and $x$ is the mass of GMP injected with the maximum load of $1.4 \mathrm{mg}$.

The purity of BioPURE-GMP estimated using this standard curve was $\sim 91 \%$, which was slightly greater than the minimal $90 \%$ purity reported by the manufacturer. The recovery rate of GMP investigated using our TCA precipitation method shows a consistent rate of $44 \pm 3 \%$ based on an initial GMP concentration of $\sim 13$ 


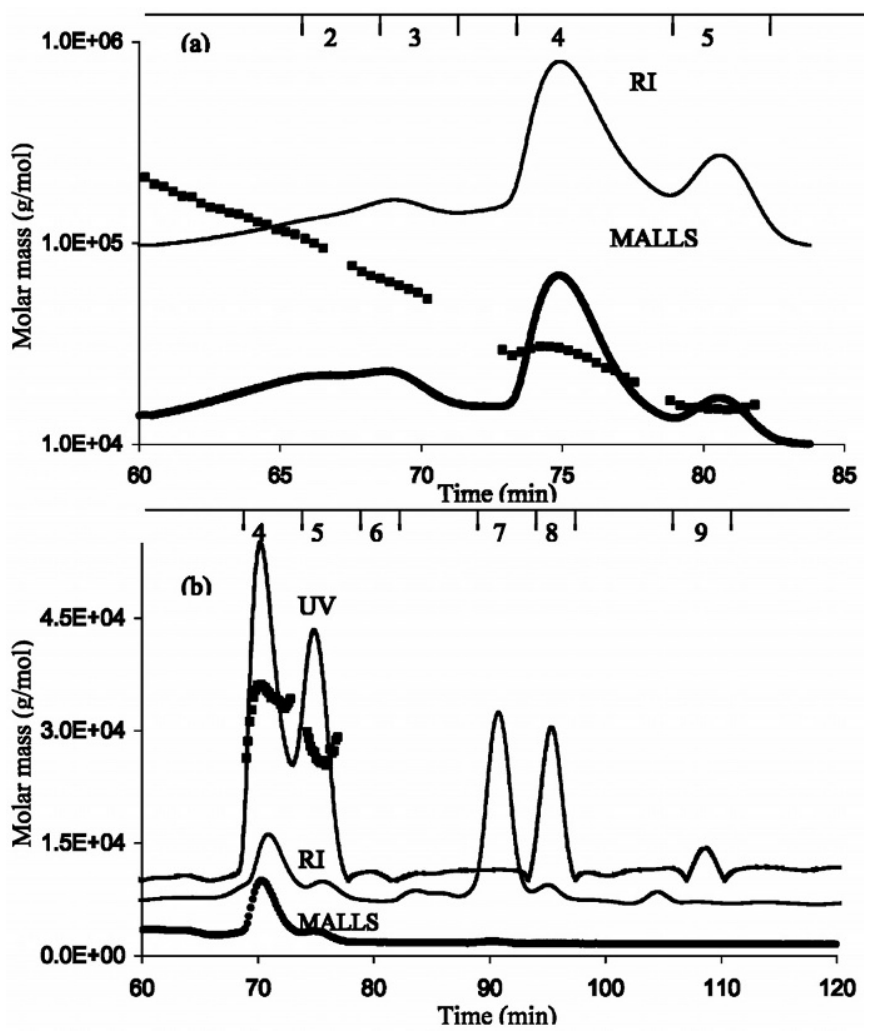

Figure 7. Size-exclusion chromatography-refractive index (SECRI) elution profile of whey protein isolate (a) and SEC-RI-UV (280 $\mathrm{nm}$ ) whet protein concentrate (b) obtained for a $4 \%$ solution that had been ultracentrifuged. The elution profile is overlaid with the calculated molar mass ( $)$ and multi-angle laser light scattering

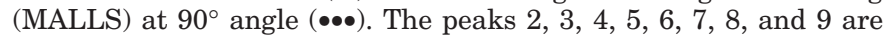
IgG, BSA, $\beta$-lactoglobulin, $\alpha$-lactoalbumin, unknown, lactose, orotic acid, and unknown NPN, respectively.

$\mathrm{mg} / \mathrm{ml}$. It is also found in our experiments that GMP recovery rate varies according to the initial GMP concentration in the solution, e.g., when the GMP concentration was $\sim 2.2 \mathrm{mg} / \mathrm{ml}$, the recovery rate was $\sim 75 \%$.
The recovery rate of GMP was lower compared to the method proposed by Lieske and Konard (1996). This may have been caused by differences in the precipitation step as they analyzed immediately after their sample was mixed and filtered. In our experiment, the TCAGMP mixture was allowed to stand overnight before centrifugation and filtration, which allowed enough time to avoid the occurrence of any additional precipitate after filtration.

The MW of GMP was also investigated. All WPI samples as well as the BioPURE-GMP had a similar MW of $\sim 8600$, which is close to the theoretical MW of 7000 to $8000 \mathrm{Da}$ (Abd El-Salam et al., 1996), although the GMP has an unusual short retention time (close to BLG). This may be due to a large hydrodynamic volume arising from the hydrophilic groups, such as sialic acid, on GMP (Minkiewicz et al., 1996). The determination of MW from our SEC-MALLS technique is not dependent on retention time or hydrodynamic volume but rather the fundamental LS properties of the polymer. The calculated GMP concentrations as well as the corresponding MW are also listed in Table 2. The SECMALLS profiles of TCA treated WPI samples are shown in Figure 8, and the absence of any contamination by BLG in our GMP peak was confirmed from the absence of any absorbance peak at $280 \mathrm{~nm}$. Samples C and D show very low GMP concentration and differ from others, which agree with its manufacturing condition, i.e., IE process. In WPI samples manufactured using membrane processing, all proteins including GMP were present.

\section{CONCLUSIONS}

SEC combined with PDA, MALLS, and DRI detectors is a powerful tool for studying the state of aggregation of commercial whey protein products. It fractionates the protein mixture according to its molecular size and

Table 3. Molecular weight (MW) comparison of major proteins in commercial whey protein isolate samples calculated from differential refractive index (DRI) and UV detectors. ${ }^{1}$

\begin{tabular}{llllllll}
\hline & \multicolumn{3}{c}{ MW from DRI $\left(\times 10^{4} \mathrm{Da}\right)$} & & \multicolumn{3}{c}{ MW from UV $\left(\times 10^{4} \mathrm{Da}\right)$} \\
\cline { 2 - 4 } \cline { 7 - 9 } Samples & BSA & BLG $^{2}$ & ALA $^{3}$ & & BSA & BLG & ALA \\
\hline A & $5.53 \pm 0.24^{\mathrm{a}}$ & $2.33 \pm 0.03^{\mathrm{a}}$ & $1.41 \pm 0.0^{\mathrm{ab}}$ & & $5.38 \pm 0.07^{\mathrm{ab}}$ & $3.18 \pm 0.06^{\mathrm{a}}$ & $1.50 \pm 0.07^{\mathrm{a}}$ \\
$\mathrm{B}$ & $5.58 \pm 0.44^{\mathrm{ab}}$ & $2.27 \pm 0.03^{\mathrm{a}}$ & $1.52 \pm 0.05^{\mathrm{ab}}$ & & $4.73 \pm 0.05^{\mathrm{ab}}$ & $3.22 \pm 0.07^{\mathrm{a}}$ & $1.56 \pm 0.05^{\mathrm{a}}$ \\
$\mathrm{C}$ & $6.53 \pm 0.13^{\mathrm{b}}$ & $2.99 \pm 0.14^{\mathrm{b}}$ & $1.57 \pm 0.04^{\mathrm{b}}$ & & $4.57 \pm 0.20^{\mathrm{ab}}$ & $3.12 \pm 0.09^{\mathrm{a}}$ & $1.55 \pm 0.04^{\mathrm{a}}$ \\
$\mathrm{D}$ & $6.67 \pm 0.10^{\mathrm{b}}$ & $3.69 \pm 0.44^{\mathrm{c}}$ & $1.50 \pm 0.01^{\mathrm{ab}}$ & & $5.27 \pm 0.22^{\mathrm{ab}}$ & $3.23 \pm 0.08^{\mathrm{a}}$ & $1.49 \pm 0.05^{\mathrm{a}}$ \\
$\mathrm{E}$ & $4.83 \pm 0.10^{\mathrm{a}}$ & $2.27 \pm 0.01^{\mathrm{a}}$ & $1.46 \pm 0.01^{\mathrm{ab}}$ & & $4.31 \pm 0.11^{\mathrm{b}}$ & $3.17 \pm 0.05^{\mathrm{a}}$ & $1.50 \pm 0.02^{\mathrm{a}}$ \\
$\mathrm{F}$ & $5.52 \pm 0.22^{\mathrm{a}}$ & $2.27 \pm 0.05^{\mathrm{a}}$ & $1.60 \pm 0.07^{\mathrm{b}}$ & & $4.52 \pm 0.64^{\mathrm{ab}}$ & $3.36 \pm 0.06^{\mathrm{a}}$ & $1.60 \pm 0.06^{\mathrm{a}}$ \\
$\mathrm{G}$ & $6.67 \pm 0.14^{\mathrm{b}}$ & $2.30 \pm 0.01^{\mathrm{a}}$ & $1.63 \pm 0.02^{\mathrm{b}}$ & & $6.26 \pm 0.13^{\mathrm{a}}$ & $3.28 \pm 0.03^{\mathrm{a}}$ & $1.67 \pm 0.06^{\mathrm{a}}$ \\
\hline
\end{tabular}

a,b,c,d,e,f Values in a column with different superscripts are significantly different $(P<0.05)$.

${ }^{1}$ Values are means \pm standard deviations for $\mathrm{n}=3$.

${ }^{2} \mathrm{BLG}=\beta$-lactoglobulin.

${ }^{3} \mathrm{ALA}=\alpha$-lactalbumin. 


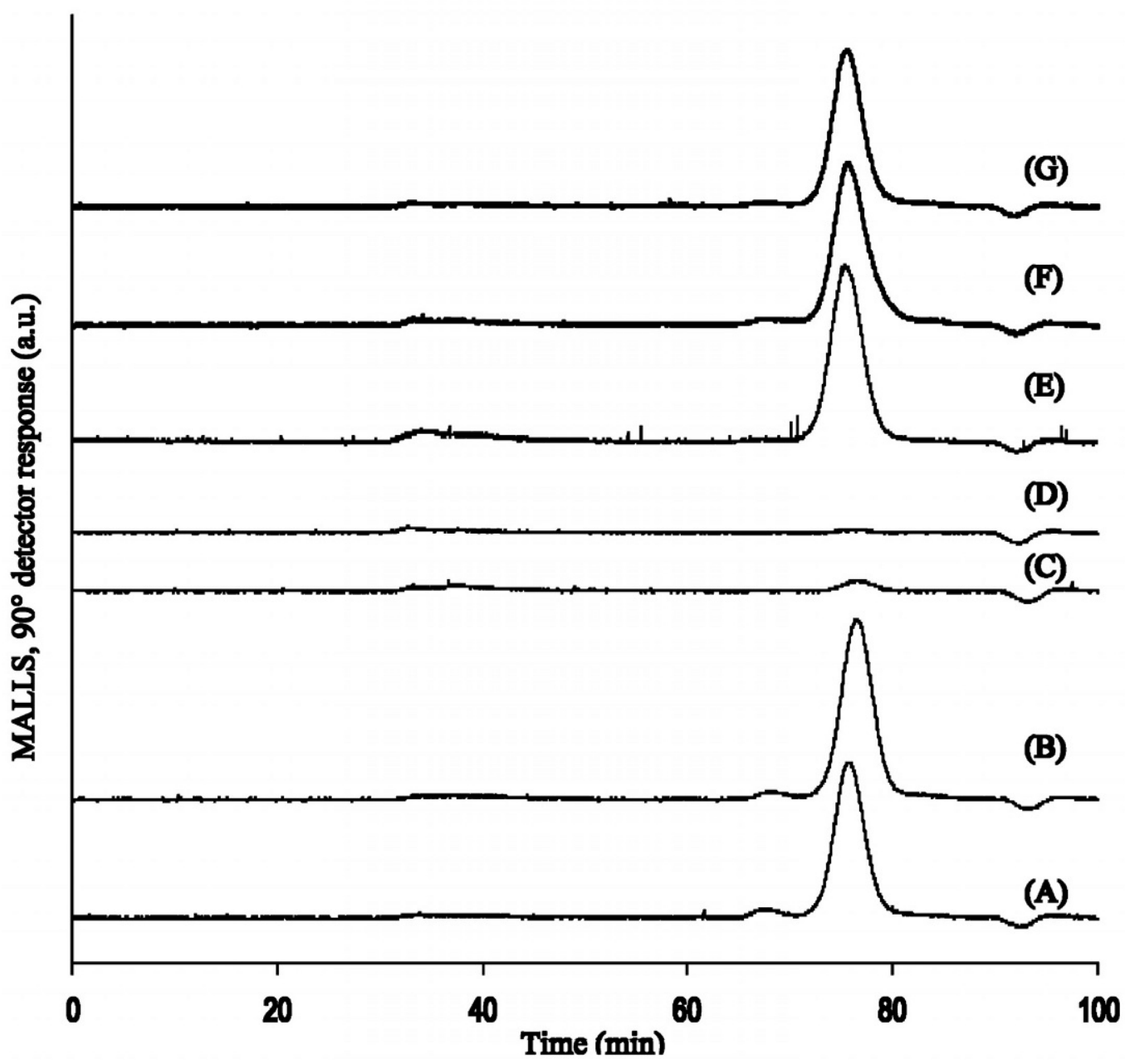

Figure 8. Size exclusion chromatography, multi-angle laser light scatering (SEC-MALLS) elution profiles for TCA-treated whey protein isolate samples (A to G) for the least squares response at $90^{\circ}$. Peaks indicate glycomacropeptide.

determines the MW and performs a spectrum analysis of the material eluting in small, individual slices of the SEC chromatogram. Our results indicated that there was always some residual lipid material present in commercial whey proteins samples. The concentration of this residual material was greatly reduced by ultracentrifugation and eliminated by using chitosan to form lipid-chitosan complexes. For different WPI samples, there were some significant differences between samples for the MW of BSA, BLG and ALA, depending on the concentration detector used. Glycomacropeptide was present at a very low concentration of WPI obtained by IE and a method to quantify GMP in whey protein products using SEC-MALLS was developed. For WPC samples, there were differences in the concentration of residual lipids (presumably reflecting differences in the efficiency of fat removal during processing). A greater concentration of minor components were found in the low protein content WPC. In general, higher concentrations of residual lipids in WPC samples made it more difficult to estimate MW of some of the individual whey proteins. The MW calculated by the UV concentration detector tended to be more consistent than DRI. Differences in functionality of commercial WPI and WPC samples could be due to the changes in protein compositions, the concentration of residual lipids and possibly mineral contents.

\section{ACKNOWLEDGMENTS}

This work was funded by Dairy Management Incorporated. The authors wish to acknowledge the assistance of Mark Etzel with GMP analysis, Jongwoo Choi with statistical analysis and Sofia Erazo with chitosan procedure. 


\section{REFERENCES}

Abd El-Salam, M. H., S. El-Shibiny, and W. Buchheim. 1996. Characteristics and potential uses of the casein macropeptide. Int. Dairy J. 6:327-341.

Bottomley, R. C., M. T. A. Evans, and C. J. Parkinson. 1990. Whey proteins. Pages 435-466 in Food Gels. P. Harris, ed. Essex: Elsevier Applied Science, Essex, UK.

Cayot, P., and D. Lorient. 1997. Structure-function relationships of whey proteins. Pages 225-256 in Food Proteins and their Applications. S. Damodaran and A. Paraf, eds. Marcel Dekker, New York, NY.

de La Fuente, M. A., Y. Hemar, M. Tamehana, P. A. Munro, and H. Singh. 2002. Process-induced changes in whey proteins during the manufacture of whey protein concentrates. Int. Dairy J. 12:361-369.

de Wit, J. N. 1990. Thermal stability and functionality of whey proteins. J. Dairy Sci. 73:3602-3612.

de Wit, J. N. 1998. Nutritional and functional characteristics of whey proteins in food products. J. Dairy Sci. 81:597-608.

de Wit, J. N., E. Hontelez-Backx, and M. Adamse. 1988. Evaluation of functional properties of whey protein concentrates and whey protein isolates. 3. Functional properties in aqueous solution. Neth. Milk Dairy J. 42:155-172.

Deshler, M. 1999. Whey protein isolates: Production, composition and nutrition facts. Nutraceuticals World. Online. Available: http:// www.nutraceuticalsworld.com/marapr99-b8.htm.

Hoffman, M. A. M., G. Sala, C. Olieman, and C. G. de Kruif. 1997. Molecular mass distributions of heat-induced $\beta$-lactoglobulin aggregates. J. Agric. Food Chem. 45:2949-2957.

Hollar, C. M., N. Parris, A. Hsieh, and K. D. Cockley. 1995. Factors affecting the denaturation and aggregation of whey proteins in heated whey protein concentrate mixtures. J. Dairy Sci. 78:260-267.

Holt, C., D. McPhail, I. Nevison, T. Nylander, J. Otte, R. H. Ipsen, R. Bauer, L. Ogendal, K. Olieman, K. G. de Kruif, J. Leonil, D. Molle, G. Henry, J. L. Maubois, M. D. Perez, P. Puyol, M. Calvo, S. M. Bury, G. Kontopidis, I. McNae, L. Sawyer, L. Ragona, L. Zetta, H. Molinari, B. Klarenbeek, M. J. Jonkman, J. Moulin, and D. Chatterton. 1999a. Apparent chemical composition of nine commercial or semi-commercial whey protein concentrates, isolates and fractions. Int. J. Food Sci. Technol. 34:543-556.

Holt, C., D. McPhail, T. Nylander, J. Otte, R. H. Ipsen, R. Bauer, L. Ogendal, K. Olieman, K. G. de Kruif, J. Leonil, D. Molle, G. Henry, J. L. Maubois, M. D. Perez, P. Puyol, M. Calvo, S. M. Bury, G. Kontopidis, I. McNae, L. Sawyer, L. Ragona, L. Zetta, H. Molinari, B. Klarenbeek, M. J. Jonkman, J. Moulin, and D. Chatterton. 1999b. Some physico-chemical properties of nine commercial or semi-commercial whey protein concentrates, isolates and fractions. Int. J. Food Sci. Technol. 34:587-601.

Huglin, M. B. 1972. Specific refractive index increments. Pages 165331 in Light Scattering from Polymer Solutions. Huglin, M. B., eds. Academic Press, Inc., New York, NY.

Hwang, D. C., and S. Damodaran. 1995. Selective precipitation and removal of lipids from cheese whey using chitosan. J. Agric. Food Chem. 43:33-37.
Kinsella, J. E., and D. M. Whitehead. 1989. Proteins in whey: Chemical, physical, and functional properties. Adv. Food Nutr. Res. 33:343-438.

Law, A. J. R., J. Leaver, J. M. Banks, and D. S. Horne. 1993. Quantitative fractionation of whey proteins by gel permeation FPLC. Milchwissenschaft 48:663-666.

Lieske, B., and G. Konrad. 1996. A new method to estimate caseinomacropeptide and glycomacropeptide from trichloroacetic acid filtrates. Milchwissenschaft 51:431-434.

Lucey, J. A., M. Srinivasan, H. Singh, and P. A. Munro. 2000. Characterization of commercial and experimental sodium caseinates by multiangle laser light scattering and size-exclusion chromatography. J. Agric. Food Chem. 48:1610-1616.

Minkiewicz, P., C. J. Slangen, F. M. Lagerwerf, J. Haverkamp, H. S. Rollema, and S. Visser. 1996. Reverse-phase high-performance liquid chromatographic separation of bovine $\kappa$-casein macropeptide and characterization of isolated fractions. J. Chromatogr. A. 743:123-135.

Morr, C. V. 1985. Composition, physicochemical and functional properties of reference whey protein concentrates. J. Food Sci. 50:1046-1421.

Morr, C. V., and E. A. Foegeding. 1990. Composition and functionality of commercial whey and milk protein concentrates and isolates: A status report. Food Technol. 44(4):100-112.

Morr, C. V., and E. Y. W. Ha. 1993. Whey protein concentrates and isolates: Processing and functional properties. CRC Crit. Rev. Food Sci. Nutr. 33:431-476.

Pace, C. N., F. Vajdos, L. Fee, G. Grimsley, and T. Gray. 1995. How to measure and predict the molar absorption coefficient of a protein Protein Chem. 4:2411-2423.

Parris, N., S. G. Anema, H. Singh, and L. K. Creamer. 1993. Aggregation of whey proteins in heated sweet whey. J. Agric. Food Chem. 41:460-464.

Patel, M. T., A. Kilara, L. M. Huffman, S. A. Hewitt, and A. V. Houlihan. 1990. Studies on whey protein concentrates. I. Compositional and thermal properties. J. Dairy Sci. 73:1439-1449.

SAS/STAT User's Guide: Statistics. 1999. Version 8.0 Edition. SAS Institute Inc., Cary, NC.

Schokker, E. P., H. Singh, and L. K. Creamer. 2001. Heat-induced aggregation of $\beta$-lactoglobulin $\mathrm{A}$ and $\mathrm{B}$ with $\alpha$-lactalbumin. Int. Dairy J. 10:843-853.

Schokker, E. P., H. Singh, D. N. Pinder, G. E. Norris, and L. K. Creamer. 1999. Characterization of intermediates formed during heat-induced aggregation of $\beta$-lactoglobulin $\mathrm{AB}$ at neutral $\mathrm{pH}$. Int. Dairy J. 9:791-800.

Shimada, K., and J. C. Cheftel. 1989. Sulfhydryl group disulphide bond interchange reactions during heat induced gelation of whey protein isolate. J. Agric. Food Chem. 37:161-168.

Walstra, P., and R. Jenness. 1984. Dairy Chemistry and Physics. John Wiley \& Sons, New York, NY.

Wen, J., T. Arakawa, and J. S. Philo. 1996. Size-exclusion chromatography with on-line light-scattering, absorbance, and refractive index detectors for studying proteins and their interactions. Anal. Biochem. 240:155-166.

Wyatt, P. J. 1993. Light scattering and the absolute characterization of macromolecules. Anal. Chim. Acta 272:1-40. 